\title{
Prevalence of CRYPTOSPoridium-LIKe INFECTION IN ONE-HUMPED CAMELS (CAMELUS DROMEDARIUS) OF NORTHWESTERN IRAN
}

\author{
YAKHCHALI M.* \& MORADI T.**
}

\section{Summary:}

Cryptosporidium is a ubiquitous enteropathogen protozoan infection affecting livestock worldwide. The present study was carried out to determine the prevalence of Cryptosporidium infection in different age groups of dromedary camels in northwestern Iran from November 2009 to July 2010. A total number of 170 fecal samples were collected and examined using modified Ziehl-Neelsen (MZN) staining under light microscope. Examination of stained fecal smears revealed that 17 camels (10\%) were positive for Cryptosporidiumlike. The prevalence of Cryptosporidium-like was significantly higher in camel calves ( $<1$ years old) $(20 \%)$ than other age groups, in which the diarrhoeic calves had the prevalence of $16 \%$. In adult camels the prevalence was $6.5 \%$. There was no significant difference in the prevalence of Cryptosporidium-like between male and female camels. It is concluded that Cryptosporidium infection is a problem in camel husbandry and could be of public health concern in the region.

KEY WORDS: Cryptosporidium, protozoan, prevalence, livestock, camel, Iran.

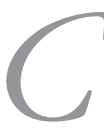
ryptosporidium species belong to the Apicomplexa phylum of parasites and have been detected in a wide range of hosts, including 155 mammalian species from many geographical regions of the world (Fayer \& Ungar, 1986; Fayer, 2004). Infected human cases with Cryptosporidium spp. had a history of being in close contact with different species of domestic animals like camels. Some of the zoonotic Cryptosporidium species (C. parvum, C. meleagridis, C. canis) usually causes self-limiting diarrhoea in human and animals and could be a great public health concern worldwide (Minas et al., 1994; De Graaf et al., 1999; Castro-Hermida et al., 2002; Causapé et al., 2002; Graczyk et al., 2003; Joachim, 2004; Caccio, 2005; Wang et al., 2008) and Iran (Mirzaei, 2007; Nahrevanian et al., 2007; Yakhchali \& Gholami, 2008; Razavi et al., 2009).

\footnotetext{
* Department of Pathobiology, Parasitology Division, Faculty of Veterinary Medicine, Nazlu campus, Urmia University, Urmia city, West Azerbaijan province, PO BOX 57153-1177, Iran.

** Laboratory technitioner in Miandoab, Iran.

Correspondence: Mohammad Yakhchali.

Tel.: 984419144463959 .

E-mail: m.yakhchali@urmia.ac.ir
}

Résumé : Prévalence de l'INFeCtion À CRYPTOSPORIDIUM CHez LE DROMADAIRE (CAMELUS DROMEDARIUS) AU NORD-OUEST DE L'IRAN Les Cryptosporidium sont des protozoaires entéropathogène qui infectent le bétail partout dans le monde. L'étude avait pour objectif de déterminer la prévalence de l'infection à Cryptosporidium chez des dromadaires de différents groupes d'âge au nord-ouest de I'Iran, de novembre 2009 à juillet 2010. Au total, 170 échantillons de fèces ont été collectés et examinés en microscopie optique après coloration de Ziehl-Neelsen modifiée (MZN). L'examen a montré que 17 dromadaires (10\%) étaient porteurs de Cryptosporidium. Chez les jeunes de moins d'un an, la prévalence (20\%) était significativement plus élevée que celle des autres groupes d'âge. La prévalence la plus élevée (16\%) a été observée chez les jeunes atteints de diarrhée, et la moins élevée (6,5\%) chez les adultes non diarrhéiques. II n'a pas été observé de différence significative de prévalence entre les males et les femelles. En conclusion, l'infection à Cryptosporidium chez les dromadaires pourrait poser un problème de santé vétérinaire dans la région.

MOTS-CLÉS : Cryptosporidium, protozoaire, prévalence, bétail, dromadaire, Iran.

The Camelidae family under the suborder Tylopoda is broken down into the Lama genus (New World Camelids) and the Camelus genus (Old World Camelids) including: Camelus bactriamus (Linnaeus, 1758; Asiatic or two-humped camel) otherwise known as the Bactrian camel and Camelus dromedarius (Linnaeus, 1758; Arabian or one-humped camel) or simply the camel (Wernery \& Kdaden 2002; Yakhchali \& Chraghi, 2007). There are about 20 million camels in North and East Africa countries, and Middle and Far East countries (Yakhchali \& Athari, 2010). In Iran, one-humped camels are important multipurpose animal. The camels are the most suitable species of domestic mammals to be used under extremely arid conditions due to physiological attributes (Oryan et al., 2008).

So far, 20 valid species of Cryptosporidium have been reported which 12 of them infecting mammals (Fayer et al., 2010) and over 40 genotypes with no species names described (Xiao et al., 2004). Livestock cryptosporidiosis may have an important economic impact because of high morbidity and sometimes high mortality rates among animals (Sunnotel et al., 2006). Despite its wide distribution and obvious relevance to animal health, Cryptosporidium prevalence in camels 
of northwestern Iran has not been yet reported and this is the first extensive and quantitative investigation on the dromedary camels' cryptosporidiosis. For this purpose, the present study was carried out to determine the prelevance of Cryptosporidium infection in one-humped camels of Iranian farms.

\section{MATERIALS AND METHODS}

\section{FIELD STUDY AREA}

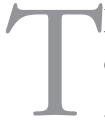

he Miandoab region is located in the southeast of West Azerbaijan province between latitude $36^{\circ} 57^{\prime} \mathrm{N}$ and longitude $46^{\circ} 06^{\prime} \mathrm{E}$ (Fig. 1). An average population of more than 200,000 dromedary camels is distributed over vast camel-raising areas in the arid and semiarid deserts of the country (Razavi et al., 2009). Approximately $0.3 \%$ of this population exist in northwestern Iran, especially in Miandoab suburban (Yakhchali \& Athari, 2010).

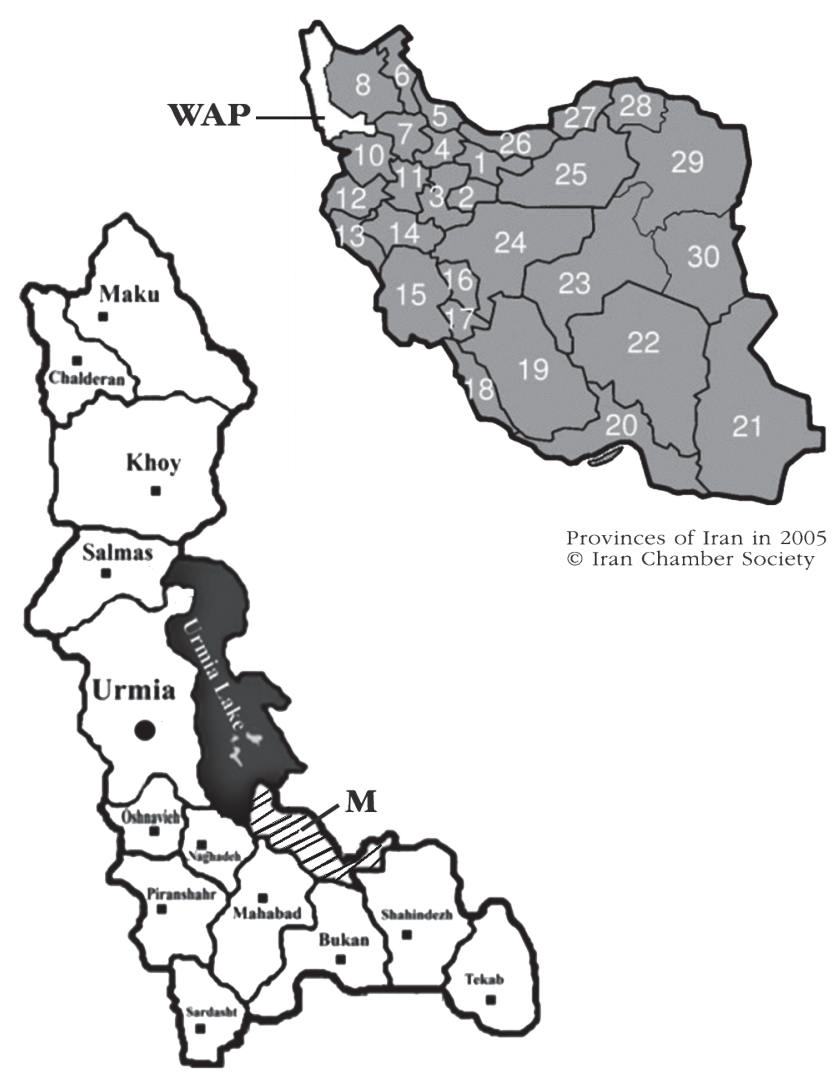

Fig. 1. - Geographical location of farms where animals sampled in northwestern Iran (M: Miandoab suburban; WAP: West Azerbaijan province).

\section{SAMPLING PROCEDURE}

The study was undertaken in the Miandoab suburban from November 2009 to July 2010. In the course of the study, a total number of 170 camels ( 85 males and 85 females) were randomly selected from camel farms using table of random numbers. Sample size was calculated according to Thrusfield (1997). The examined camels were crossbred and indigenous which reared traditionally. For each animal, age and sex were recorded. The age was determined on the basis of eruption of permanent incisor teeth (Smallwood, 1992). The animals were divided into four groups, namely young camel calves (less than one year old), immature (two-three years old), adult (four-five years old) and old (more than five years old). The animals subjected to a clinical examination including general body condition, heart and respiratory rates and signs of diarrhoea.

In each farm, fecal sample was collected directly from the rectum using sterile plastic gloves. The samples were transported to the laboratory in a cool box and then stored for a maximum of $24 \mathrm{~h}$ before analysis. The feces were classified according to their consistency as diarrhoeic (D) and non-diarrhoeic (ND).

\section{SAMPLE PROCESSING}

One hundred and seventy stool samples were examined in the study. Each camel was numbered and subjected to a clinical examination. The collected fecal samples of each animal were examined by direct smear techniques. To determine oocysts shedding, the negative faecal samples by direct smear examination were concentrated by centrifugal sedimentation $(2,500$ $\mathrm{rpm}$ for $2 \mathrm{~min}$ ) and Clayton-Lane flotation techniques using standard Sheather solution (sg 1.12) (Soulsby, 1982; Hendrix, 1998). The presence of Cryptosporidium-like oocysts in all samples was confirmed by modified Ziehl-Neelsen (MZN) staining (Henricksen \& Polenz, 1981). The diameter of 100 Cryptosporidiumlike oocysts of each infected camel was measured at $1,000 \times$ magnification. Each positive sample was considered when at least one oocyst with the correct morphologic characters was observed (Cryptosporidium-like oocysts were $4-6 \mu \mathrm{m}$ and spherical containing a residuum, sporozoites and usually within a clear halo, against a blue background) (Soulsby, 1982; Baxby et al., 1984).

\section{STATISTICAL ANALYSIS}

Statistical evaluation was undertaken to compare the prevalence among different age groups and gender with confidence interval of $95 \%$ using non-parametric Chi-square and $t$ tests (SPSS for Windows). Probability value of $<0.05$ was regarded statistically significant. 


\section{RESULTS}

The overall prevalence of Cryptosporidium species among the examined camels was $10 \%$ (17/170) (Table I). The parasite genus identification of the oocysts was confirmed by morphology. The oocysts were nearly spherical in shape and contained four sporozoites. The average size $( \pm \mathrm{SD})$ of the oocysts was $5.70(0.49) \times 4.74(0.3) \mu \mathrm{m}$ (range 5.20-6.10 × 3.90-4.98 $\mu \mathrm{m}$ ) with shape index (length/ width) of 1.19 (0.05, range 1.08-1.26). These morphological characters nearly fit with the description of Cryptosporidium-like oocysts (Fig. 2).

Camel calves (< one year old) had the highest prevalence, with an overall average of $20 \%$ in the course of study. The prevalence was significantly higher $(p<0.05)$ in camel calves compared to the other age groups (Table I). Some of the infected animals showed wasting, diarrhoea and debility. Older camels with shedding oocysts in faeces did not show symptoms of cryptosporidiosis. The highest prevalence of Cryptosporidium species in D animals was $16 \%$ in camel calves. While in ND cases, it was $10 \%$ for adult camels (Table I). The oldest animal shedding Cryptosporidium-like oocysts was 4.5 years old. No old camels were infected with Cryptosporidium species at any time during the study.

The prevalence of infection in male and female examined camels indicated that five $(6 \%)$ male and 12 (14\%) female had Cryptosporidium infection. Infection rate was highest in female camels (33\%) with less than one year old. There was no significant difference in the prevalence between male and female camels in all age groups $(p>0.05)$.

\begin{tabular}{|c|c|c|c|c|c|c|}
\hline \multirow{2}{*}{$\begin{array}{l}\text { Age } \\
\text { (year) }\end{array}$} & \multirow{2}{*}{$\begin{array}{l}\text { No. of examined } \\
\text { animals }\end{array}$} & \multirow{2}{*}{$\begin{array}{l}\text { No. of infected } \\
\text { animals }\end{array}$} & \multirow{2}{*}{$\begin{array}{c}\text { Prevalence }(\mathbf{n} / \mathbf{N}) \\
(\%)\end{array}$} & \multirow{2}{*}{$\begin{array}{c}\text { Oocyst shedding } \\
(\%)\end{array}$} & \multicolumn{2}{|c|}{ Fecal consistency $(\%)$} \\
\hline & & & & & $\mathbf{D}$ & ND \\
\hline$<1^{\mathrm{a}}$ & 44 & 9 & 20.0 & 78 & 16 & 5 \\
\hline $2-3$ & 65 & 4 & 6.0 & 17 & 3 & 3 \\
\hline $4-5$ & 41 & 4 & 6.5 & 5 & 0 & 10 \\
\hline$>5$ & 20 & 0 & 0.0 & 0 & 0 & 0 \\
\hline Total & 170 & 17 & 10.0 & 100 & 5 & 5 \\
\hline
\end{tabular}

a: $\chi^{2}$ test $(p<0.05)$; D: diarrhoeic; $n$ : number of infected animals; $N$ : number of examined animals; ND: non-diarrhoeic.

Table I. - The prevalence of Cryptosporidium infection, oocysts shedding and faecal consistency, in different age groups of naturally infected camels in Miandoab suburb, Iran $(n=170)$.

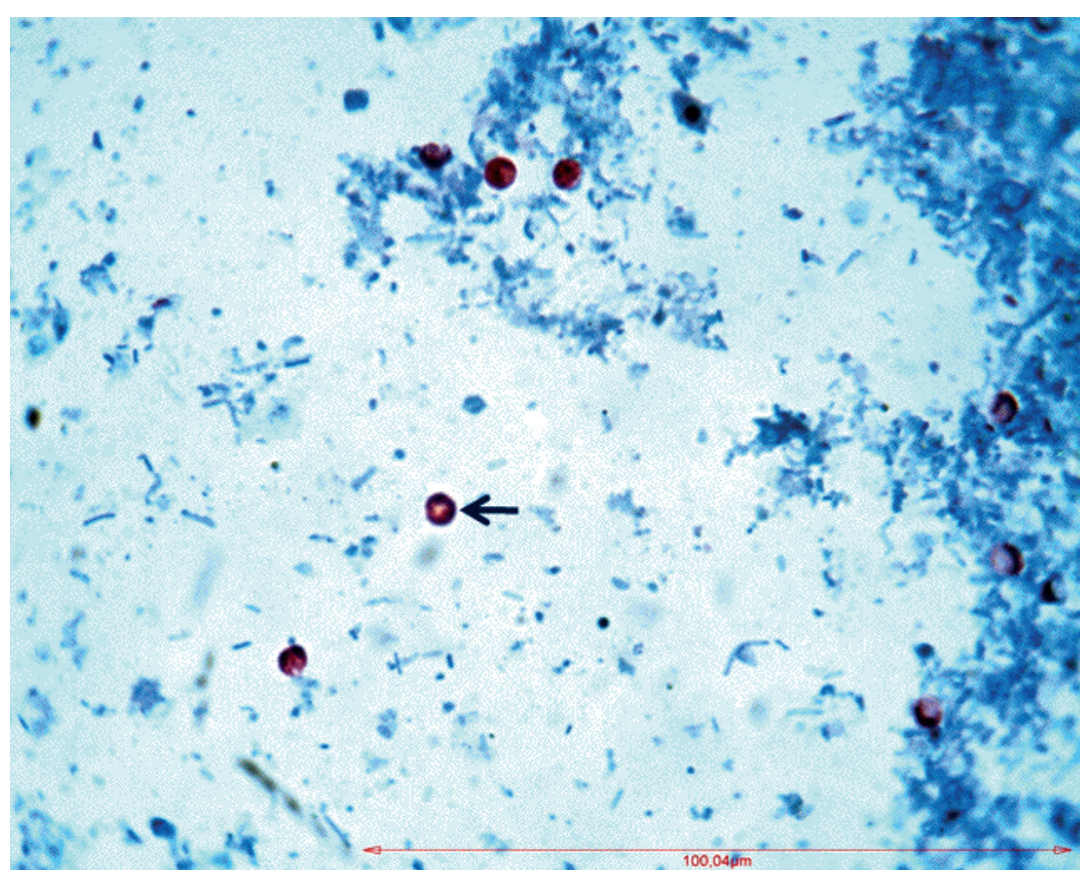

Fig. 2. - Cryptosporidium-like oocysts stained by modified Ziehl-Neelsen (MZN) method (arrow head, 1,000 $\times$ ). 


\section{DISCUSSION}

C ryptosporidium biology, distribution pattern, pathology and prevalence have been reported in many countries throughout the world. However, it is restricted to domestic ruminants (cattle, sheep and goats) and limited data is available in other herbivores including camels (Nouri, 2002; Razavi et al., 2009). The results of present study revealed that Cryptosporidium infection occurred also in one-humped camels of northwestern Iran with low prevalence. The prevalence in naturally infected camels of Iran was reported in north-east (1.9\%) (Borji et al., 2009), south (37.9\%) (Razavi et al., 2009) and Qeshm Island in Persian golf (16.9\%) (Nazifi et al., 2010). Saleh \& Mahran (2007), El Kelesh et al. (2009), Abdel-Wahab \& AbdelMaogood (2011) noted that camel Cryptosporidium infection rate in Egypt varied between 3.37-19.30 \%. These variations could be due to the difference in the environmental condition and hygienic measures.

In this study, age of examined camel calves had significant effect on prevalence compared to other age groups. According to Lorenzo et al. (1993), Scott et al. (1995) and Olson et al. (1997), young animals are much more susceptible to the infections than adult ones in other animals. These findings suggest that the age-related distribution of Cryptosporidium infection in this age group is not similar to that previously reported in camels (Soltane et al., 2007; Borji et al., 2009; Razavi et al., 2009). It seems that the adult camels (three-four years old) with low prevalence, having normal formed of faeces (ND) and no clinical symptoms of cryptosporidiosis served as carriers for young camels.

The sex of examined camels had no significant effect on prevalence. With respect to this finding, the current study is in concordance with other researches (Chalmers et al., 1997; Bull et al., 1998; Razavi et al., 2009). No infection in old camels (> five years old), even when camel calves were infected, suggests that immunity does develop in older animals (Fayer, 2004). It is therefore camels to be as healthy carriers and sources of Cryptosporidium infection for human beings and other animals. The infected animals can shed oocysts into the environment and remain as a source of infection to other animals and humans (Xiao et al., 1993). Hence, some of the Cryptosporidium species (C.parvum, C. meleagridis and C. canis) are of zoonotic concern and could be of great public health concern in the region (Graczyk et al., 2003).

Camel husbandry has been considered a sector of food supply for rural and sometimes urban people in this geographical region of Iran. Thus, their health status is important and epidemiological investigation on Cryptosporidium infections is useful to launch an all-round control programmed in this area. Therefore, further investigations will reveal more information about economic effects of this parasite and public health concern in the region.

\section{ACKNOWLEDGEMENTS}

The authors thank Mr. K. Badali from Parasitology Laboratory of Urmia Faculty of Veterinary Medicine for technical assistance and owners of the region for their cooperation in the field study.

\section{REFERENCES}

ABDEl-WAHAB A. \& ABDEL-MaOgOOD S. Identification of Cryptosporidium species infecting camels (Camelus dromedarius) in Egypt. Journal of American Science, 2011, 7 (2), 609-612.

BaXby D., Blundell N. \& Hart C.A. The development and performance of a simple sensitive method for the detection of Cryptosporidium oocysts in faeces. Journal of Hygiene Cambridge, 1984, 99, 317-323.

Borji H., Razmi Gh., Movassaghi A.R., Naghibi A.G. \& Maleki M. Prevalence of Cryptosporidium and Eimeria infections in dromedary (Camelus dromedarius) in abattoir of Mashhad, Iran. Journal of Camel Practice and Research, 2009, 16 (2), 167-170

Bull S.A., Chalmers R.M., Sturdee A.P. \& Healing T.D. A survey of Cryptosporidium species in Skomer bank voles (Clethrionomys glareolus skomerensis). Journal of Zoology, 1998, 244, 119-122.

Caccio S.M. Molecular epidemiology of human cryptosporidiosis. Parassitologia, 2005, 47, 185-192.

Castro-Hermida J.A., Gonzalez-Losada Y.A. \& Ares-Mazas E. Prevalence and risk factors involved in the spread of neonatal bovine cryptosporidiosis in Galicia (NW Spain). Veterinary Parasitology, 2002, 106, 1-10.

Causapé A.C., Quilez J., Sanchez-Acedo C., Del Cacho E. \& LOPEZ-BERnAD F. Prevalence and analysis of potential risk factors for Cryptosporidium parvum infection in lambs in Zaragoza (northeastern Spain). Veterinary Parasitology, 2002, 104, 287-298.

Chalmers R.M., Sturdee A.P., Bull S.A., Miller A. \& Wright S.E. The prevalence of Cryptosporidium parvum and $C$. muris in Mus domesticus, Apodemus sylvaticus and Clethrionomys glareolus in an agricultural system. Parasitology Research, 1997, 83, 478-482.

De Graaf D.C., Vanopdenbosch E., Ortega-Mora L.M., Abbasi H. \& PeETERS J.E. A review of the importance of cryptosporidiosis in farm animals. International Journal for Parasitology, 1999, 29, 1269-1287.

El Kelesh E.A., Abdel-Maogood S.Z. \& Abdel-Wahab A.M. Comparative studies on some Cryptosporidium species infecting different animals. Egyptian Veterinary Medical Society of Parasitology Journal, 2009, 5, 19-36. 
FAYER R. \& Ungar B.L.P. Cryptosporidium spp. and cryptosporidiosis. Microbiology Reviews, 1986, 50, 458-483.

FAYER R. Cryptosporidium: a water-borne zoonotic parasite. Veterinary Parasitology, 2004, 126, 37-56.

FAYER R. Taxonomy and species delimitation in Cryptosporidium. Experimental Parasitology, 2010, 124, 90-97.

Graczyk T.K., Grimse B.H., Knight R., DaSilva A.J., Pieniazek N.J. \& VeAL D.A. Detection of Cryptosporidium parvum and Giardia lamblia carried by synanthropic flies by combined fluorescent in situ hybridization and a monoclonal antibody. American Journal of Tropical Medicine and Hygiene, 2003, 68, 228-232.

Hendrix C.M. Diagnostic Veterinary Medicine, $2^{\text {nd }}$ edition. Mosby Publishers, St. Louis, 1998, 257-259.

Henricksen S.A. \& Polenz J.F. Staining of Cryptosporidia by modified Ziehl-Neelsen technique. Acta Veterinaria Scandinavica, 1981, 22, 594-596.

JOACHIM A. Human cryptosporidiosis: an update with special emphasis on the situation in Europe. Journal of Veterinary Medicine. B, Infectious Diseases and Veterinary Public Health, 2004, 51, 251-259.

Minas A., Koutsoukou-Hartona W. \& Papasavvas M. Epidemiological survey of diarrhoeic faeces of lambs and kids for cryptosporidial oocysts in the Larissa region. Bulletin of the Hellenic Veterinary Medical Society, 1994, 44, 112114.

Mirzaei M. Prevalence of Cryptosporidium sp. infection in diarrhoeic humans in Iran. The Korean Journal of Parasitology, 2007, 45, 133-137.

Nahrevanian H., Assmar M. \& Ghorbani Samin M. Cryptosporidiosis among immunocompetent patients with gastroenteritis in Iran: a comparison with other enteropathogenic parasites. Journal of Microbiology, Immunology and Infection, 2007, 40, 154-156.

Nazifi S., Behzadi M.A., Haddadi S.H., RaAyat Jahromi A., Mehrshad S. \& Amadon A. Prevalence of Cryptosporidium isolated from dromedary camels (Camelus dromedarius) in Qeshm Island, Southern Iran. Comparative Clinical Pathology, 2010, 19, 311-314.

Nouri M. A Cryptosporidium muris like parasite in cattle and camels in Iran. Indian Veterinary Journal, 2002, 79, 558-559.

OrYan A., VAlinezhad A. \& Bahrami S. Prevalence and pathology of camel filariasis in Iran. Parasitology Research, 2008, 103, 1125-1131.

Razavi S.M., Oryan A., Bahrami S., Mohammadalipour A. \& GOWHARI M. Prevalence of Cryptosporidium infection in camels (Camelus dromedarius) in a slaughterhouse in Iran. Tropical Biomedicine, 2009, 26 (3), 267-273.

SALEH M.A. \& MAHRAN O.M. A preliminary study on cryptosporidiosis in dromedary camels at Shalatin Area, Egypt. Assiut Veterinary Medical Journal, 2007, 53 (112), 195208.

SMALLWOOD J.E. A guided tour of veterinary anatomy. W.B. Saunders Company, Philadelphia, 1992, 322-323.

Soltane R., Guyot K., Dei-Cas E. \& Ayadi A. Cryptosporidium parvum (Eucoccidiorida: Cryptosporiidae) in calves: results of a longitudinal study in a dairy farm in Tunisia. Parasite, 2007, 14, 309-312.

SoulsBy E.J.L. Helminths, Arthropods and Protozoa of domesticated animals, $7^{\text {th }}$ edition. Bailliere Tindall, London, 1982.

Sunnotel O., Lowery C.J., Moore J.E., Dooley J.S.G., XiaO L. \& Millar B.C. Cryptosporidium. Letters in Applied Microbiology, 2006, 43, 7-16.

Thrusfield M. Veterinary Epidemiology, $2^{\text {nd }}$ edition. Blackwell Sciences, Oxford, 1997, 182.

Wang R., Zhang L., Ning C., Feng Y., Jian F., XiaO L., Lu B., AI W. \& Dong H. Multilocus phylogenetic analysis of Cryptosporidium andersoni (Apicomplexa) isolated from a Bactrian camel (Camelus bactrianus) in China. Parasitology Research, 2008, 102, 915-920.

WERNERY U. \& KDADEN O.R. Infectious diseases in camelids. Blackwell Sciences, Oxford, 2002, 3-17.

Xiao L., Herd R.P. \& Rings D.M. Diagnosis of Cryptosporidium on a sheep farm with neonatal diarrhoea by immunofluorescense assays. Veterinary Parasitology, 1993, $47,17-22$.

XiaO L.H., FAyer R., Ryan U. \& Upton S.J. Cryptosporidium taxonomy: recent advances and implications for public health. Clinical Microbiology, 2004, 17, 72-97.

YAKHCHALI M. \& Chraghi E. Eimeriosis in bacterian and dromedary camels in the Miandoab region, Iran. Acta Veterinaria (Beograd), 2007, 57 (5-6), 545-552.

Yakhchali M. \& Gholami E. Prevalence of Eimeria and Cryptosporidium spp. in cattle of Sanandaj city (Kurdistan province), Iran. Journal of Pajouhesh and Sazandegi, 2008, 87, 81-87 (in Persian with English abstract).

YakHChali M. \& Athari SH. A study on prevalence of Eimeria spp. infection in camels of Tabriz region. Archives of Razi Institute, 2010, 65 (2), 111-115.

Received on July $1^{\text {st }}, 2011$ Accepted on September 30 ${ }^{\text {th }}, 2011$ 